\title{
Keynotes
}

\section{Antidepressants in the treatment of anxiety disorder}

\author{
Peter Tyrer, Professor of Community Psychiatry, St Mary's Hospital Medical School, \\ London W10 6DZ; and Cosmo Hallstrom, Consultant Psychiatrist, \\ Charing Cross Hospital, London W6 8RF
}

Antidepressants are increasingly being used for the treatment of anxiety disorders, although they are not specifically licensed for this indication. This has come about partly because of concern over the problem of benzodiazepine dependence and the search for alternative, and preferably better, treatments. Antidepressants and other treatments have proved to be an effective alternative to benzodiazepines despite having more unwanted effects and a delayed onset of action. They may even be more effective than benzodiazepines and their benefits are alleged to be independent of concurrent depressive symptomatology. What is the evidence in favour of these claims?

\section{Background}

The early findings of Klein that imipramine was effective in the treatment of panic attacks, and was unconnected with the presence of depression, led to a major change in the classification of anxiety disorders and the introduction of a new diagnosis, panic disorder, associated with paroxysmal attacks of anxiety occurring in the apparent absence of provoking stimuli. The classification that has resulted has been embraced most warmly in the United States but is also being followed in the new ICD-10 classification, and so a similar division is adopted here. One related diagnosis, obsessive compulsive disorder (obsessional neurosis), is not discussed under this heading because it is felt to be distinct from other anxiety disorders.

\section{Agoraphobia, social phobia and panic disorder}

In a series of studies, the original tricyclic antidepressant, imipramine, has been shown to be significantly superior to placebo in the treatment of panic attacks associated with agoraphobia (Zitrin et al, 1983; Cross-National Collaborative Panic Study, second phase investigators, 1992). There is a delay in the onset of the anti-anxiety effects of between two and five weeks as with depressive dis- order, although sedative effects are noted immediately. Panic and restlessness may increase in the first days of treatment and in general the drop-out rates in the early weeks of treatment are greater than for benzodiazepines (Cross-National Panic Study, second phase investigators, 1992). Imipramine is of equivalent efficacy to alprazolam, the most popular treatment of panic disorder in the USA, but, perhaps predictably, alprazolam acts more quickly. For alprazolam to be effective it is recommended in high doses (e.g. about $6 \mathrm{mg} /$ day) and, as this adds to the risk of dependence, in this respect it compares unfavourably with imipramine.

There remains some doubt as to the optimal dose of imipramine needed to achieve therapeutic effects in panic. The generally accepted daily dose for the treatment of anxiety is the same as that in depression (about 100-150 mgs daily) but in panic the dosage rate quoted is much larger (between 3 (sic) \& $300 \mathrm{mgs} /$ day), and while this is too great to make clinical sense it is probably wise to build up dosage gradually. Whether imipramine acts by blocking panic attacks, reducing phobic avoidance, or primarily treating depressed mood, is far from clear, and is a subject of much controversy (Marks, 1983). Although these arguments are not resolved it does appear that depressed mood is not essential for clinical improvement and so the anti-anxiety effects appear to be independent of other moods.

Whether other antidepressants show any selectivity in panic is far from clear. However, fluvoxamine, a selective 5-HT re-uptake inhibitor, has been shown to be more effective in reducing panic attacks than the selective noradrenaline re-uptake inhibitor antidepressant, maprotiline (Den Boer \& Westenberg, 1988). It appears that the anti-anxiety effects of antidepressants are completely independent of sedative antihistaminic or anticholinergic effects.

Monoamine oxidase inhibitors may also be at least as effective, and possibly more so, than conventional anti-depressants for the treatment of panic, agoraphobia and social phobia. For the hydrazine MAOIs (e.g. isocarboxazid, phenelzine) there is a delay of between two and six weeks before the onset of 
antidepressant action but this is shorter for the nonhydrazine, tranylcypromine. However, this drug is the most dangerous of the MAOIs. There are particular claims that monoamine oxidase inhibitors are effective in social phobias (Liebowitz et al, 1985).

\section{Generalised anxiety disorder}

This diagnosis, which can be loosely summarised as "left over anxiety" when phobias and panic have been removed, does not have the same diagnostic precision as the other disorders. It has also been studied less intensively. Nevertheless, several studies have shown that antidepressants are generally superior to conventional anti-anxiety drugs such as benzodiazepines, provided that they are given for four weeks or longer, although benzodiazepines act more quickly (Kahn et al, 1986; Tyrer et al, 1988).

\section{Mixed anxiety and depression}

In clinical practice mixed anxiety and depressive disorders are the norm rather than the exception, and it becomes an academic argument which mood state should take priority. Since the pioneering work of Eve Johnstone and her colleagues (1980) which demonstrated that in these mixed disorders antidepressants were more effective than benzodiazepines both when anxiety and depression were the predominant emotions, there have been other studies that have reinforced this finding (Lipman et al, 1986; Tyrer et al, 1988).

When set against this evidence, the continual arguments over the sub-classifications of depression and anxiety seem even less relevant. This is particularly so in general practice where most of these conditions are seen and treated. If mixed symptoms are present antidepressants are generally effective.

The place for the newer antidepressants in this group is not clear. However, there is some evidence, which although largely circumstantial, has been to some extent confirmed after initial studies with zimeldine and related drugs (Evans et al, 1986; Hudson \& Pope, 1990) that mixed anxiety-depressive syndrome might respond at least as well to these drugs as to the conventional tricyclic antidepressants. More evidence on this important subject is needed as well as the extent of compliance with these new compounds. Monamine oxidase inhibitors also have a spectrum of activity which shows less efficacy in severe depression than other antidepressants but is of greater value in the mixed anxiety-depressive disorders (Tyrer \& Shawcross, 1988).

In summary, antidepressants are at least as effective as conventional anti-anxiety drugs after they have had adequate time to achieve their clinical actions (i.e. after a period of at least four weeks) and should be regarded as among the preferred treatments for anxiety if long-term treatment is recommended. This is because the risks of dependence with the major group of anti-anxiety agents, the benzodiazepines, becomes steadily greater after regular treatment of four weeks or more.

There is also a case for treating patients with a combination of an antidepressant and a benzodiazepine in the first two weeks of treatment until the anti-anxiety effects of the antidepressant are shown. Antidepressants should not be held back by their nomenclature; they are anxiolytic too.

\section{References}

Cross-National Collaborative Panic Study: Phase InvestiGATORS (1992) Drug treatment of panic disorder: comparative efficacy of alprazolam, imipramine and placebo. British Journal of Psychiatry, 160, 191-202.

Den Boer, J. A. \& Westenberg, H. G. (1988) Effect of a serotonin and noradrenalin uptake inhibitor in panic disorder. International Clinical Psychopharmacology, 3, 59-74.

Evans, L., KenARDY, J., SCHNEIDER, P. et al (1986) Effect of a selective serotonin uptake inhibitor in agoraphobia with panic attacks: a double-blind comparison of zimeldine, imipramine and placebo. Acta Psychiatrica Scandinavica, 73, 49-53.

Hudson, J. I. \& POPE, H. G., Jr (1990) Affective spectrum disorder: does antidepressant response identify a family of disorders with a common pathophysiology? American Journal of Psychiatry, 147, $552-564$.

Johnstone, E. C., Cunningham-OWens, D. G., Frith, C. D. et al (1980) Neurotic illness and its response to anxiolytic and antidepressant treatment. Psychological Medicine, 10, 321-328.

KAHN, R. J., MCNAIR, D. M., LIPMAN, R. S. et al (1986) Imipramine and chlordiazepoxide in depressive and anxiety disorders: II. Efficacy in anxious out-patients. Archives of General Psychiatry. 43, 79-85.

Liebowitz, M. R., Gorman, J. M., Fyer, A. J. et al (1985) Social phobia: review of a neglected anxiety disorder. Archives of General Psychiatry, 42, 729-736.

Lipman, R. S., Covi, L., Rickels, K. et al (1986) Imipramine and chlordiazepoxide in depressive and anxiety disorders: I. Efficacy in depressed out-patients. Archives of General Psychiatry, 43, 68-77.

MARKs, I. M. (1983) Are there anti-compulsive or anti-phobic drugs? Review of the evidence. British Journal of Psychiatry, 140, 338-347.

TYrer, P. \& ShawCross, C. (1988) Monoamine-oxidase inhibitors in anxiety disorders. Journal of Psychiatric Research, 22, Suppl. 1, 87-98.

-, SeiveWright, N., MURPhY, S. et al (1988) The Nottingham study of neurotic disorder; comparison of drug and psychological treatments. Lancet, ii, 235-240.

Zitrin, C. M., KLeIN, D. F., WoERner, N. G. et al (1983) Treatment of phobias. 1. Comparison of imipramine hydrochloride and placebo. Archives of General Psychiatry, 40, 125-138.

A full list of references is available on request to the authors.

This paper was prepared at the request of the Psychopharmacology Working Party of the Royal College of Psychiatrists and has been approved by the Working Party. 